\title{
Molecular typing of multi-drug resistant Acinetobacter baumannii isolates from clinical and environmental specimens in three Iranian hospitals by pulsed field gel electrophoresis
}

Ali Mohammadi Bardbari ${ }^{1}$, Parviz Mohajeri ${ }^{2}$, Mohammad Reza Arabestani ${ }^{1}$, Manoochehr Karami ${ }^{3}$, Fariba Keramat ${ }^{4,5}$, Saba Asadollahi ${ }^{2}$, Amir Khodavirdipour ${ }^{6}$ and Mohammad Yousef Alikhani ${ }^{1,5^{*}}$ (I)

\begin{abstract}
Background: Multi-drug resistant (MDR) Acinetobacter baumannii is one of the most important causes of nosocomial infections. The purpose of this study was to identify antibiotic resistance patterns, biofilm formation and the clonal relationship of clinical and environmental isolates of A. baumannii by Pulsed Field Gel Electrophoresis method. Forty-three clinical and 26 environmental isolates of the MDR A. baumannii were collected and recognized via API 20NE. Antibiotic resistance of the isolates was assessed by the disk diffusion method, and the biofilm formation test was done by the microtiter plate method. Pulsed Field Gel Electrophoresis (PFGE) was used to assess the genomic features of the bacterial isolates.

Results: The resistance rate of clinical and environmental isolates against antibiotics were from 95 to $100 \%$. The difference in antibiotic resistance rates between clinical and environmental isolates was not statistically significant $(p>0.05)$. Biofilm production capabilities revealed that $31(44.9 \%)$, and $30(43.5 \%)$ isolates had strong and moderate biofilm producer activity, respectively. PFGE typing exhibited eight different clusters (A, B, C, D, E, F, G, and H) with two significant clusters included $A$ and $G$ with 21 (30.4\%) and 16 (23.2\%) members respectively, which comprises up to $53.6 \%$ of all isolates. There was no relationship between biofilm formation and antibiotic resistance patterns with PFGE pulsotypes.

Conclusions: The results show that there is a close relationship between environmental and clinical isolates of $A$. baumannii. Cross-contamination is also very important that occurs through daily clinical activities between environmental and clinical isolates. Therefore, in order to reduce the clonal contamination of MDR A. baumannii environmental and clinical isolates, it is necessary to use strict infection control strategies.
\end{abstract}

Keywords: A.baumannii, MDR, Biofilm formation, Antibiotic resistance, PFGE

\footnotetext{
*Correspondence: alikhani43@yahoo.com; alikhani@umsha.ac.ir

'Department of Microbiology, Faculty of Medicine, Hamadan University of Medical Sciences, Hamadan, Iran

${ }^{5}$ Brucellosis Research Center, Hamadan University of Medical Sciences, Hamadan, Iran

Full list of author information is available at the end of the article
}

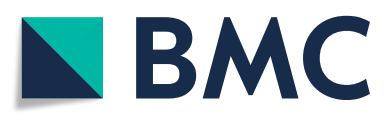

(- The Author(s). 2020 Open Access This article is licensed under a Creative Commons Attribution 4.0 International License, which permits use, sharing, adaptation, distribution and reproduction in any medium or format, as long as you give appropriate credit to the original author(s) and the source, provide a link to the Creative Commons licence, and indicate if changes were made. The images or other third party material in this article are included in the article's Creative Commons licence, unless indicated otherwise in a credit line to the material. If material is not included in the article's Creative Commons licence and your intended use is not permitted by statutory regulation or exceeds the permitted use, you will need to obtain permission directly from the copyright holder. To view a copy of this licence, visit http://creativecommons.org/licenses/by/4.0/. The Creative Commons Public Domain Dedication waiver (http://creativecommons.org/publicdomain/zero/1.0/) applies to the data made available in this article, unless otherwise stated in a credit line to the data. 


\section{Background}

Acinetobacter baumannii is a gram-negative bacterium and one of the important pathogens of nosocomial infections, including pneumonia, meningitis, bacteremia, urinary tract infections, surgical wounds and soft tissue infections [1]. It has a key role in worldwide nosocomial infections, especially in the adult intensive care units (ICUs) [2, 3]. Due to numerous factors, including prolonged hospital admission, loss of the skin barrier, and complex treatment protocols, patients admitted to ICU wards are significantly susceptible to nosocomial infections [4].

Recently, due to the use of broad-spectrum antibiotics, antimicrobial resistance between A. baumannii isolates has increased significantly. Therefore, the emergence of multi-drug resistant (MDR) and extensively drugresistant (XDR) A. baumannii isolates as an important cause of nosocomial infections is one of the major health problems in different countries of the world $[2,5,6]$. The impervious outer membrane and environmental exposure to a large pool of resistance genes are considered as selective pressures that cause XDR isolates in these bacteria [7]. This pathogen possesses a remarkable ability to survive and widely spreading in hospital environments and mucosal surfaces [8]. Long-term survival is likely to be a major cause of hospital transmission of this organism, especially in ICU wards and through healthcare staff [1]. For this reason, particular attention has been paid to the capability of $A$. baumannii to cause outbreaks of nosocomial infections and to obtain resistance to antibiotics [4]. The ability of $A$. baumannii to form biofilms on living and non-living surfaces is an important factor in the persistence of bacteria because it protects them against environmental stress conditions, such as desiccation and exposure to antibiotics and disinfectants, which makes biofilm infections persistent and challenging to treat [9]. For epidemiological studies, several typing methods have been used to investigate outbreaks caused by $A$. baumannii. The usually applied methods focus on differences in the phenotypic properties that have insufficient reproducibility and discriminatory power. Molecular approaches such as PFGE that compare the DNA differences of bacteria have been accepted because of establishing the clonal association in many bacteria including $A$. baumannii isolates [10]. So far, few investigations have been done on the relationship between environmental and clinical isolates of $A$. baumannii in patients admitted to intensive care units. Concurrent typing of clinical and environmental isolates of $A$. baumannii is an important tool for finding sources and ways of transmission of such epidemic isolates. This research aimed to identify antibiotic resistance patterns, biofilm formation and clonal association of clinical and environmental isolates of $A$. baumannii by PFGE technique.

\section{Results}

\section{Susceptibility to antibiotics}

The results of the antimicrobial susceptibility test shown in Fig. 1. All clinical and environmental isolates of $A$. baumannii (100\%) were susceptible to colistin and tigecycline and all isolates (100\%) were resistant to ciprofloxacin and cefepime. The resistance rate against ampicillin-sulbactam, meropenem, imipenem, and amikacin in the clinical isolates were 43(100\%), 42(97.7\%), $42(97.7 \%), 43(100 \%)$ and in environmental isolates were 24(92.3\%), 26(100\%), 25(96.2\%), and 23(88.5\%), respectively. Most clinical (95.3\%) and environmental (84.6\%) isolates of $A$. baumannii were resistant to all tested antibiotics and designated as extensively drug-resistance (XDR). The difference in antibiotic resistance rates between clinical and environmental isolates was not statistically significant $(p>0.05)$.

\section{Biofilm formation}

One of the major virulence-related features of $A$. baumannii is the ability of biofilm formation. Therefore, we decided to measure potential biofilm formation in XDR of clinical and environmental isolates. In our study, we found that $68(98.6 \%)$ of the isolates were capable of forming biofilm. The mean OD 595 values for clinical and environmental isolates were $0.680 \pm 0.289$ and $0.540 \pm 0.265$, respectively. Biofilm production capabilities revealed that 31 (44.9\%), 30 (43.5\%), 7 (10.2\%), and 1 (1.4\%) isolates had strong, moderate, weak, and no biofilm producer activity in the microplate assay, respectively. No statistically significant difference in biofilm formation was seen among the clinical and the environmental isolates $(p>0.05)$.

\section{PFGE results}

The PFGE method by ApaI enzyme was used for access typing and genetic relationship between the A.baumannii isolated from clinical and environmental samples. From 26 environmental and 43 clinical isolates, 8 common PFGE clusters (A, B, C, D, E, F, G, and $\mathrm{H}$ were obtained (Fig. 1). The similar strains in two hospital were seen. PFGE clusters A, E, and F were seen in the clinical and environmental isolates that recovered from Besat hospital. PFGE cluster A was the predominant clones with 21 members, which of them, 13 members isolated from patients and 8 from environmental surfaces (Table 1).

\section{Discussion}

Acinetobacter baumannii is becoming an increasingly well-known pathogen because of the increase in the number of infections caused by this organism and the development of MDR and XDR strains [11]. The potential of $A$. baumannii to persist in either moist or dry 

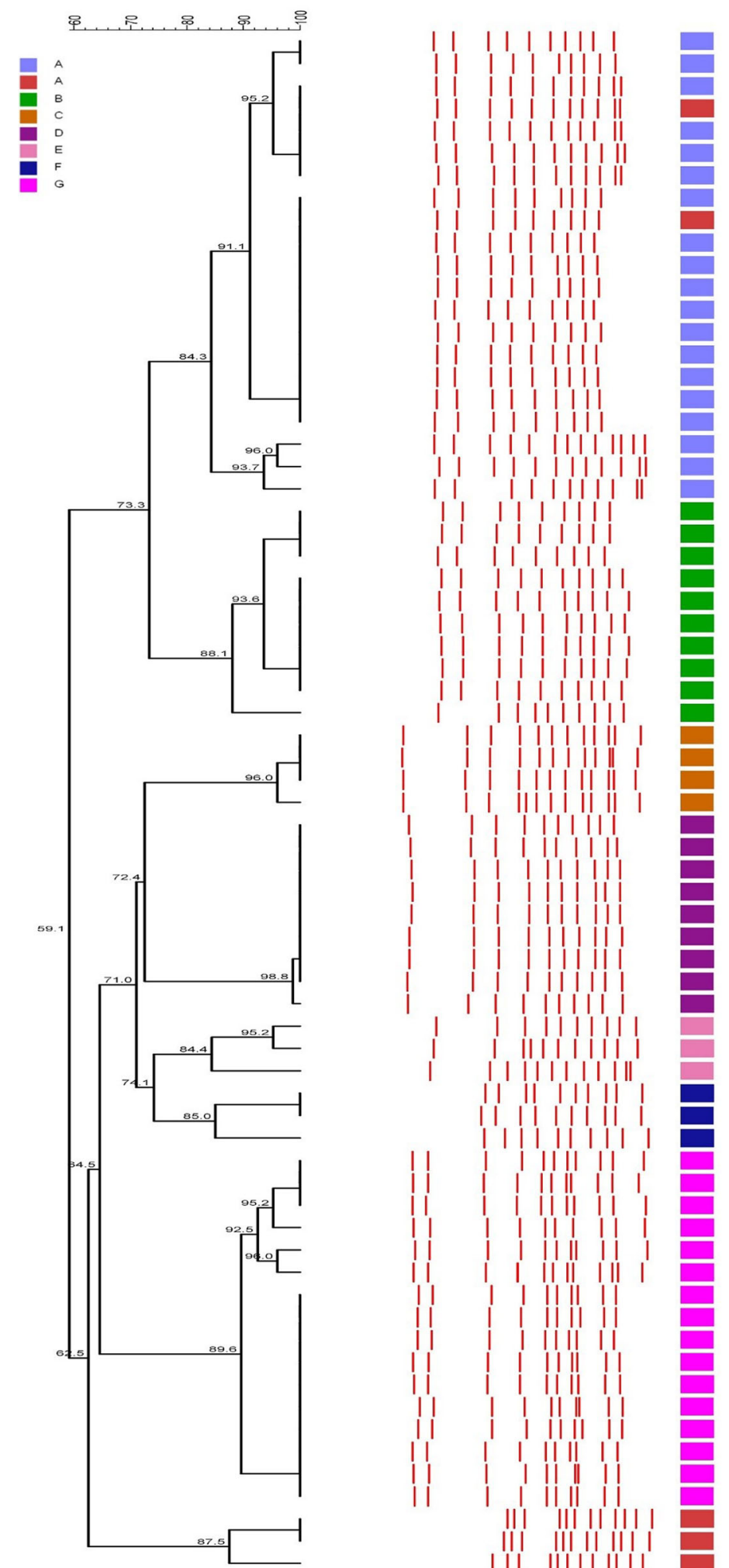

\begin{tabular}{|c|c|c|c|c|c|c|c|c|c|}
\hline 竎 & 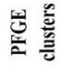 & 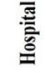 & $\bar{n}$ & y & है & in & $\underline{\Xi}$ & हె & $\begin{array}{l}\text { 븐 } \\
\text { 을 }\end{array}$ \\
\hline Clin41 & $\mathbf{A}$ & H1 & $\mathbf{R}$ & $\mathbf{R}$ & $\mathbf{R}$ & $\mathbf{R}$ & $\mathbf{R}$ & $\mathbf{R}$ & I \\
\hline Env2 & A & H1 & $\mathbf{R}$ & $\mathbf{R}$ & $\mathbf{R}$ & $\mathbf{R}$ & $\mathbf{R}$ & $\mathbf{R}$ & I \\
\hline Clin38 & A & H1 & $\mathbf{R}$ & $\mathbf{R}$ & R & $\mathbf{R}$ & $\mathbf{R}$ & $\mathbf{R}$ & \\
\hline Clin5 & $\mathbf{A}$ & H3 & $\mathbf{R}$ & $\mathbf{R}$ & $\mathbf{R}$ & $\mathbf{R}$ & $\mathbf{R}$ & $\mathbf{R}$ & I \\
\hline Env9 & A & HI & $\mathbf{R}$ & $\mathbf{R}$ & $\mathbf{R}$ & $\mathbf{R}$ & $\mathbf{R}$ & $\mathbf{R}$ & \\
\hline Env8 & A & H1 & $\mathbf{R}$ & $\mathbf{R}$ & $\mathbf{R}$ & $\mathbf{R}$ & $\mathbf{R}$ & $\mathbf{R}$ & \\
\hline Clin43 & A & H1 & $\mathbf{R}$ & $\mathbf{R}$ & $\mathbf{R}$ & $\mathbf{R}$ & $\mathbf{R}$ & $\mathbf{R}$ & 5 \\
\hline Clin6 & $\mathbf{A}$ & H1 & $\mathbf{R}$ & $\mathbf{R}$ & $\mathbf{R}$ & $\mathbf{R}$ & $\mathbf{R}$ & $\mathbf{R}$ & 1 \\
\hline Clin31 & $\mathbf{A}$ & H3 & $\mathbf{R}$ & $\mathbf{R}$ & $\mathbf{R}$ & $\mathbf{R}$ & $\mathbf{R}$ & $\mathbf{R}$ & \\
\hline Env6 & $\mathbf{A}$ & H1 & $\mathbf{R}$ & $\mathbf{R}$ & $\mathbf{R}$ & $\mathbf{R}$ & $\mathbf{R}$ & $\mathbf{R}$ & \\
\hline Clin28 & $\mathbf{A}$ & H1 & $\mathbf{R}$ & $\mathbf{R}$ & $\mathbf{R}$ & $\mathbf{R}$ & $\mathbf{R}$ & $\mathbf{R}$ & \\
\hline Clin29 & $\mathbf{A}$ & H1 & $\mathbf{R}$ & $\mathbf{R}$ & $\mathbf{R}$ & $\mathbf{R}$ & $\mathbf{R}$ & $\mathbf{R}$ & $\mathrm{v}$ \\
\hline Env1 & $\mathbf{A}$ & H1 & $\mathbf{R}$ & $\mathbf{R}$ & $\mathbf{R}$ & $\mathbf{R}$ & $\mathbf{R}$ & $\mathbf{R}$ & \\
\hline Clin32 & $\mathbf{A}$ & H1 & $\mathbf{R}$ & $\mathbf{R}$ & $\mathbf{R}$ & $\mathbf{R}$ & $\mathbf{R}$ & $\mathbf{R}$ & $\mathrm{s}$ \\
\hline Env5 & A & H1 & $\mathbf{R}$ & $\mathbf{R}$ & $\mathbf{R}$ & $\mathbf{R}$ & $\mathbf{R}$ & $\mathbf{R}$ & 1 \\
\hline Clin36 & A & H1 & $\mathbf{R}$ & $\mathbf{R}$ & $\mathbf{R}$ & $\mathbf{R}$ & $\mathbf{R}$ & $\mathbf{R}$ & $\mathbf{I}$ \\
\hline Env4 & $\mathbf{A}$ & H1 & $\mathbf{R}$ & $\mathbf{R}$ & $\mathbf{R}$ & $\mathbf{R}$ & $\mathbf{R}$ & $\mathbf{R}$ & w \\
\hline Env3 & A & H1 & $\mathbf{R}$ & $\mathbf{R}$ & $\mathbf{R}$ & $\mathbf{R}$ & $\mathbf{R}$ & $\mathbf{R}$ & 1 \\
\hline Clin8 & $\mathbf{A}$ & H1 & $\mathbf{R}$ & $\mathbf{R}$ & $\mathbf{R}$ & $\mathbf{R}$ & $\mathbf{R}$ & $\mathbf{R}$ & I \\
\hline Clin9 & A & H1 & $\mathbf{R}$ & $\mathbf{R}$ & R & $\mathbf{R}$ & $\mathbf{R}$ & $\mathbf{R}$ & $\mathbf{s}$ \\
\hline Clin37 & $\mathbf{A}$ & H1 & $\mathbf{R}$ & $\mathbf{R}$ & $\mathbf{R}$ & $\mathbf{R}$ & $\mathbf{R}$ & $\mathbf{R}$ & $\mathbf{S}$ \\
\hline Clin24 & B & $\mathrm{H}_{2}$ & $\mathbf{R}$ & $\mathbf{R}$ & R & $\mathbf{R}$ & $\mathbf{R}$ & $\mathbf{R}$ & $\mathbf{I}$ \\
\hline Env11 & B & $\mathrm{H}_{2}$ & $\mathbf{R}$ & $\mathbf{R}$ & $\mathbf{R}$ & $\mathbf{R}$ & $\mathbf{R}$ & $\mathbf{R}$ & $\mathbf{I}$ \\
\hline Clin3 & B & H2 & $\mathbf{R}$ & $\mathbf{R}$ & $\mathbf{R}$ & $\mathbf{R}$ & $\mathbf{R}$ & $\mathbf{R}$ & $\mathbf{s}$ \\
\hline Clin17 & B & H2 & $\mathbf{R}$ & $\mathbf{R}$ & $\mathbf{R}$ & $\mathbf{R}$ & $\mathbf{R}$ & $\mathbf{R}$ & $\mathbf{s}$ \\
\hline Clin20 & B & H2 & $\mathbf{R}$ & $\mathbf{R}$ & $\mathbf{R}$ & $\mathbf{R}$ & $\mathbf{R}$ & $\mathbf{R}$ & s \\
\hline Clin21 & B & H2 & $\mathbf{R}$ & $\mathbf{R}$ & $\mathbf{R}$ & $\mathbf{R}$ & $\mathbf{R}$ & $\mathbf{R}$ & w \\
\hline Env18 & B & H2 & $\mathbf{R}$ & $\mathbf{R}$ & R & $\mathbf{R}$ & $\mathbf{R}$ & $\mathbf{R}$ & s \\
\hline Env17 & B & $\mathrm{H}_{2}$ & $\mathbf{R}$ & $\mathbf{R}$ & $\mathbf{R}$ & $\mathbf{R}$ & $\mathbf{R}$ & $\mathbf{R}$ & I \\
\hline Clin7 & B & H2 & $\mathbf{R}$ & $\mathbf{R}$ & $\mathbf{R}$ & $\mathbf{R}$ & $\mathbf{R}$ & $\mathbf{R}$ & $\mathrm{N}$ \\
\hline Clin42 & B & H2 & $\mathbf{R}$ & $\mathbf{R}$ & $\mathbf{R}$ & $\mathbf{R}$ & $\mathbf{R}$ & $\mathbf{R}$ & s \\
\hline Clin2 & C & H3 & $\mathbf{R}$ & $\mathbf{R}$ & $\mathbf{R}$ & $\mathbf{R}$ & $\mathbf{R}$ & $\mathbf{R}$ & $\mathbf{s}$ \\
\hline Env15 & C & H3 & $\mathbf{R}$ & $\mathbf{R}$ & $\mathbf{R}$ & $\mathbf{R}$ & $\mathbf{R}$ & $\mathbf{R}$ & s \\
\hline Env16 & C & $\mathrm{H}_{3}$ & $\mathbf{R}$ & $\mathbf{R}$ & $\mathbf{R}$ & $\mathbf{R}$ & $\mathbf{R}$ & $\mathbf{R}$ & I \\
\hline Clin4 & C & H3 & $\mathbf{R}$ & $\mathbf{R}$ & $\mathbf{R}$ & $\mathbf{R}$ & $\mathbf{R}$ & $\mathbf{R}$ & s \\
\hline Clin14 & D & H2 & $\mathbf{R}$ & $\mathbf{R}$ & $\mathbf{R}$ & $\mathbf{R}$ & $\mathbf{R}$ & $\mathbf{R}$ & I \\
\hline Clin27 & D & H2 & $\mathbf{R}$ & $\mathbf{R}$ & $\mathbf{R}$ & $\mathbf{R}$ & $\mathbf{R}$ & $\mathbf{R}$ & I \\
\hline Env16 & D & H2 & $\mathrm{s}$ & s & $\mathbf{R}$ & $\mathbf{R}$ & $\mathbf{R}$ & $\mathbf{R}$ & I \\
\hline Env14 & D & H2 & $\mathbf{R}$ & $\mathbf{R}$ & $\mathbf{R}$ & $\mathbf{R}$ & $\mathbf{R}$ & $\mathbf{R}$ & I \\
\hline Clin33 & D & $\mathrm{H}_{2}$ & $\mathbf{R}$ & $\mathbf{R}$ & $\mathbf{R}$ & $\mathbf{R}$ & $\mathbf{R}$ & $\mathbf{R}$ & I \\
\hline Env12 & D & $\mathrm{H} 2$ & $\mathbf{R}$ & $\mathbf{R}$ & $\mathbf{R}$ & $\mathbf{R}$ & $\mathbf{R}$ & $\mathbf{R}$ & $\mathbf{S}$ \\
\hline Clin23 & D & H2 & $\mathbf{R}$ & $\mathbf{R}$ & $\mathbf{R}$ & $\mathbf{R}$ & $\mathbf{R}$ & $\mathbf{R}$ & w \\
\hline Clin12 & D & $\mathrm{H}_{2}$ & $\mathbf{R}$ & $\mathbf{R}$ & $\mathbf{R}$ & $\mathbf{R}$ & $\mathbf{R}$ & $\mathbf{R}$ & w \\
\hline Env13 & D & $\mathrm{H}_{2}$ & $\mathbf{R}$ & $\mathbf{R}$ & $\mathbf{R}$ & $\mathbf{R}$ & $\mathbf{R}$ & $\mathbf{R}$ & I \\
\hline Clin15 & $\mathbf{E}$ & H1 & $\mathbf{R}$ & $\mathbf{R}$ & $\mathbf{R}$ & $\mathbf{R}$ & $\mathbf{R}$ & $\mathbf{R}$ & I \\
\hline Env7 & $\mathbf{E}$ & H1 & $\mathbf{R}$ & $\mathbf{R}$ & $\mathbf{R}$ & $\mathbf{R}$ & $\mathbf{R}$ & $\mathbf{R}$ & I \\
\hline Clin1 & $\mathbf{E}$ & H1 & $\mathbf{R}$ & $\mathbf{R}$ & $\mathbf{R}$ & $\mathbf{R}$ & $\mathbf{R}$ & $\mathbf{R}$ & $\mathrm{s}$ \\
\hline Clin18 & $\mathbf{F}$ & H1 & $\mathbf{R}$ & $\mathbf{R}$ & $\mathbf{R}$ & $\mathbf{R}$ & $\mathrm{s}$ & $\mathbf{R}$ & I \\
\hline Clin35 & $\mathbf{F}$ & H1 & $\mathbf{R}$ & $\mathbf{R}$ & $\mathbf{R}$ & $\mathbf{R}$ & $\mathbf{R}$ & $\mathbf{R}$ & $\mathrm{s}$ \\
\hline Env22 & $\mathbf{F}$ & H1 & $\mathbf{R}$ & $\mathbf{R}$ & $\mathbf{R}$ & $\mathbf{R}$ & $\mathbf{R}$ & $\mathbf{R}$ & s \\
\hline Env25 & G & H3 & $\mathrm{s}$ & $\mathbf{R}$ & $\mathbf{R}$ & $\mathbf{R}$ & $\mathbf{R}$ & $\mathbf{R}$ & s \\
\hline Clin34 & G & H3 & $\mathbf{R}$ & $\mathbf{R}$ & $\mathbf{R}$ & $\mathbf{R}$ & $\mathbf{R}$ & $\mathbf{R}$ & $\mathrm{s}$ \\
\hline Env21 & G & H3 & $\mathbf{R}$ & $\mathbf{R}$ & $\mathbf{R}$ & $\mathbf{R}$ & $\mathbf{R}$ & $\mathbf{R}$ & $\mathbf{w}$ \\
\hline Clin30 & G & $\mathrm{H}_{3}$ & $\mathbf{R}$ & $\mathbf{R}$ & $\mathbf{R}$ & $\mathbf{R}$ & $\mathbf{R}$ & $\mathbf{R}$ & I \\
\hline Clin16 & G & $\mathrm{H}_{3}$ & $\mathbf{R}$ & $\mathbf{R}$ & $\mathbf{R}$ & $\mathbf{R}$ & $\mathbf{R}$ & $\mathbf{R}$ & $\mathbf{s}$ \\
\hline Env26 & G & H3 & $\mathbf{R}$ & $\mathrm{s}$ & $\mathbf{R}$ & $\mathbf{R}$ & $\mathbf{R}$ & $\mathbf{R}$ & s \\
\hline Clin11 & G & H3 & $\mathbf{R}$ & $\mathbf{R}$ & $\mathbf{R}$ & $\mathbf{R}$ & $\mathbf{R}$ & $\mathbf{R}$ & $\mathrm{s}$ \\
\hline Env24 & G & H3 & $\mathbf{R}$ & $\mathbf{s}$ & ${ }^{R}$ & $\mathbf{R}$ & s & $\mathbf{R}$ & $\mathbf{S}$ \\
\hline Clin13 & $\mathbf{G}$ & $\mathrm{H}_{3}$ & $\mathbf{R}$ & $\mathbf{R}$ & $R^{R}$ & $\mathbf{R}$ & R & $\mathbf{R}$ & $\mathrm{s}$ \\
\hline Clin22 & G & H3 & $\mathbf{R}$ & $\mathbf{R}$ & $\mathbf{R}$ & $\mathbf{R}$ & $\mathbf{R}$ & $\mathbf{R}$ & s \\
\hline Clin26 & G & H3 & $\mathbf{R}$ & $\mathbf{R}$ & $\mathbf{R}$ & $\mathrm{s}$ & $\mathbf{R}$ & $\mathbf{R}$ & $\mathbf{s}$ \\
\hline Env19 & G & H3 & $\mathbf{R}$ & $\mathbf{R}$ & $\mathbf{R}$ & $\mathbf{R}$ & $\mathbf{R}$ & $\mathbf{R}$ & I \\
\hline Clin40 & G & H3 & $\mathbf{R}$ & $\mathbf{R}$ & R & $\mathbf{R}$ & $\mathbf{R}$ & $\mathbf{R}$ & s \\
\hline Clin39 & G & $\mathrm{H}_{3}$ & $\mathbf{R}$ & $\mathbf{R}$ & $\mathbf{R}$ & $\mathbf{R}$ & $\mathbf{R}$ & $\mathbf{R}$ & I \\
\hline Clin25 & G & H3 & $\mathbf{R}$ & $\mathbf{R}$ & $\mathbf{R}$ & $\mathbf{R}$ & $\mathbf{R}$ & $\mathbf{R}$ & $\mathrm{s}$ \\
\hline Env20 & G & H3 & $\mathbf{R}$ & $\mathbf{R}$ & $R^{R}$ & $\mathbf{R}$ & $\mathbf{R}$ & $\mathbf{R}$ & I \\
\hline $1 v 23$ & H & H2 & $\mathbf{R}$ & $\mathbf{R}$ & $\mathbf{R}$ & $\mathbf{R}$ & $\mathbf{R}$ & $\mathbf{R}$ & I \\
\hline in10 & $\mathrm{H}$ & H2 & $\mathbf{R}$ & $\mathbf{R}$ & $\mathbf{R}$ & $\mathbf{R}$ & $\mathbf{R}$ & $\mathbf{R}$ & \\
\hline in19 & H & 12 & $\mathbf{R}$ & $\mathbf{R}$ & $\mathbf{R}$ & $\mathbf{R}$ & $\mathbf{R}$ & $\mathbf{R}$ & \\
\hline
\end{tabular}

Fig. 1 Dendrogram cluster analysis of PFGE data for clinical and environmental A.baumannii isolates. Clin; clinical, Env; environmental, H1; Besat hospital, H2; Behashti hospital, H3; Sina hospital, R; resistance, SAM; ampicillin-sulbactam, AK; amikacin, CIP; ciprofloxacin, MEM; meropenem, IPM; imipenem, CPM; cefepime, N; non-biofilm producer, W; weak, l; intermediate, and S; strong biofilm producer 
Table 1 The frequency distribution of A. baumannii in clinical and environmental isolates based on the location of specimen collection and PFGE type

\begin{tabular}{lllll}
\hline Pattern & Clinical isolates No (\%) & Environmental isolates No (\%) & Total No (\%) & Status of pulsotypes \\
\hline A & $13(30.2)$ & $8(30.8)$ & $21(30.4)$ & Major pulsotype \\
B & $7(16.3)$ & $3(11.5)$ & $10(14.5)$ & Intermediate pulsotype \\
C & $2(4.6)$ & $2(7.7)$ & $4(5.8)$ & Minor pulsotype \\
D & $5(11.6)$ & $4(15.4)$ & $9(13.0)$ & Intermediate pulsotype \\
E & $2(4.6)$ & $1(3.8)$ & $3(4.3)$ & Minor pulsotype \\
F & $2(4.6)$ & $1(3.8)$ & $3(4.3)$ & Minor pulsotype \\
G & $10(23.3)$ & $6(23.1)$ & $16(23.2)$ & Major pulsotype \\
H & $2(4.6)$ & $1(3.8)$ & $3(4.3)$ & Minor pulsotype \\
Total & $43(100)$ & $26(100)$ & $69(100)$ & - \\
\hline
\end{tabular}

conditions in the hospital environment is a consequence of the presence of multiple antibacterial resistance genes and biofilm formation makes this bacterium a successful pathogen among nosocomial bacteria [12]. The unique ability of this bacterium to survive in the environment for a long time demonstrates its role in the outbreaks of nosocomial infections [13]. Contaminated environmental surfaces can contribute directly to the transmission of pathogens to patients or from the hands of health care workers to patients [14].

The results of this study show high environmental pollution in the three intensive care units in our area. The incidence of XDR A. baumannii isolated from environmental surfaces $22(84.6 \%)$ which, were resistant to all tested antibiotics was greater than that detected in previous studies in Germany (7.3\%), United States (9.8\%), and $13.1 \%$ in China $[1,13,15]$. These results can probably be attributed to inappropriate strategies of disinfection and hand washing by health workers in hospitals. Furthermore, 41(95.3\%) clinical isolates were resistant to all tested antibiotics and were XDR, which agrees with other investigations conducted in Iran $[16,17]$. Of the 8 antimicrobials tested, the most potent ones were colistin and tigecycline (100\%) for all clinical and environmental isolates. In agreement with previously research who requested, the most effective drug in controlling A. baumannii is polymyxin B [18].

Of the 41 XDR A. baumannii strains isolated from patients' respiratory tracts, the bacteria isolated from tracheal aspirate specimens were the most common respiratory isolates, which is consistent with previous studies $[19,20]$. Consistent with the earlier study, the resistance rate of clinical and environmental isolates of $A$. baumannii to antibiotics was $95-100 \%$ and there was no significant difference between antibiotic resistance in clinical and environmental isolates $(p>0.05)$ [21]. One of the important features related to the virulence of $A$. baumannii is its ability to form biofilms. In our study, we determined that $68(98.6 \%)$ isolates of XDR $A$. baumannii formed biofilm, which is in agreement with previous studies [2, 17, 22]. According to our results, $44.9 \%$ of isolates showed strong ability to biofilm formation. Our results are consistent with previous reports which showed that more than $75 \%$ of $A$. baumannii isolates form biofilms [23, 24]. Previous studies have reported a positive relationship between biofilm formation and antibiotic resistance in A. baumannii isolates [17, $25,26]$. In our study, all strong biofilm forming A. baumannii isolates were XDR.

To track and evaluate the outbreaks, the genetic association of the isolates, and to attribute one strain to the relevant clonal lineage, several molecular typing techniques have been developed [27, 28]. Among these methods, PFGE is considered the gold standard due to its discriminatory power, reproducibility, and sensitivity, and to determine the single-colonal pattern of hospital outbreaks, the prevalence of pathogens within and between hospitals and their stability in the environment are used [28].

In the current study typing of XDR A. baumannii isolates was done for tracks of outbreak and analyses of a population survey of bacteria based on their genotypes, predominant genotypes, distribution and probability transmission of isolates between patient and environmental surfaces. By the PFGE technique, 43 clinical and 26 environmental $A$. baumannii isolates were typed. PFGE typing showed 8 different PFGE cluster (A, B, C, $\mathrm{D}, \mathrm{E}, \mathrm{F}, \mathrm{G}$, and $\mathrm{H}$ ) with two major cluster $\mathrm{A}$ and $\mathrm{G}$ with $21(30.4 \%)$ and 6 (23.2\%) members, respectively, which contains up to $53.6 \%$ of all isolates. In our study, a close genetic relationship between clinical and environmental isolates of $A$. baumannii was observed that is consistent with other studies $[4,21]$. These results indicate that the hospital environment is frequently colonized by different A. baumannii clones, which may be responsible for the transmission of A. baumannii isolates between patients and their surroundings.

In our study, two clinical isolates (No 5 and 31) which were found in two distinct hospitals were clustered into 
pulsotype A. This issue may indicate the possible transfer of related isolates from one ICU to another in the same hospital or different hospitals from patients admitted to the ICUs or the hospital health team in the same city. This type of transmission has been reported in several countries $[2,29]$. Comparing the frequency of biofilm formation ability in clinical and environmental isolates with pulsotypes, no significant correlation was found, which is consistent with the study of Wroblewska et al. [30].

In our study, the correlation analysis of PFGE typing and antibiotic resistance profiles showed that most isolates were XDR and no difference in antibiotic resistance was found in the PFGE clusters. Therefore, there is no significant relationship between different PFGE clusters and antimicrobial resistance patterns. This indicates that antimicrobial resistance patterns have low discriminatory power for bacterial typing and highlights the necessity of genotyping techniques such as PFGE to categorize isolates with similar phenotypes and distinct genetic relatedness during the evaluation of outbreak episodes or horizontal transmission of isolates in the hospital environments [31].

\section{Conclusions}

Our investigation shown the high frequency of biofilm forming XDR $A$. baumannii with a high prevalence of biofilm formation. Tracing the sources of environmental isolates indicates that there is a close genetic link between environmental and clinical isolates of A. baumannii. Besides, it suggests that the occurrence of crosscontamination events is likely to occur between environmental and clinical isolates during routine clinical activities. Therefore, the use of strict infection control strategies to reduce cross-contamination of endemic clones of A. baumannii isolates is essential.

\section{Methods}

\section{Bacterial isolates}

In this cross-sectional study, 43 MDR A. baumannii were collected from respiratory tracts of patients admitted to ICU wards of Besat, Sina, and Beheshti educational hospitals of Hamadan University of Medical Sciences in Hamadan, west of Iran, during a period between November 2015 and August 2016.

The Besat hospital is a major tertiary referral hospital where patients are referred from neighboring provinces and Sina and Beheshti hospitals have infectious and internal medicine departments respectively, which accept patients in Hamadan province. Simultaneously, 26 MDR A. baumannii strains isolated from different environments and equipment surfaces such as ventilators, sink, and ground, hands of Staff, trolleys, bedside table, pillow and linens. For sampling from the environment and equipment of ICU wards, an area of about $10 \mathrm{~cm} 2$ was selected and sampled using a sterile humidified swab with physiological serum.

\section{Culture and identification}

After taking the samples, the swabs were inoculated in Brian heart infusion broth (BHI) media and incubated overnight at $35^{\circ} \mathrm{C}$ and further subcultured on MacConkey's agar plates at $37^{\circ} \mathrm{C}$ for $24 \mathrm{~h}$. The Acinetobacter spp. were identified by colony morphology, growth at $44^{\circ} \mathrm{C}$, oxidase, OF (Oxidation and fermentation), Simon citrate, and API 20NE system (BioMérieux Co, France). The A. baumannii isolates identification was confirmed by PCR of the blaOXA-51 gene. A. baumannii ATTC 19606 was used as a reference strain [32].

\section{Antibacterial susceptibility test}

Antimicrobial susceptibility test was accomplished by the Kirby-Bauer disk diffusion method using the ampicillin/ sulbactam $(10 \mu \mathrm{g} / 10 \mu \mathrm{g})$, imipenem $(10 \mu \mathrm{g})$, meropenem $(10 \mu \mathrm{g})$, amikacin $(30 \mu \mathrm{g})$, cefepime $(30 \mu \mathrm{g})$, colistin $(10 \mu \mathrm{g})$, tigecycline $(15 \mu \mathrm{g})$, and ciprofloxacin $(5 \mu \mathrm{g})$, antibiotic disks (Mast Group Co, UK). The results interpreted according to Clinical and Laboratory Standard Institute guidelines (CLSI) [33]. Pseudomonas aeruginosa ATCC 27853 was used as a control strain. MDR A. baumannii isolates were defined as resistant to three or more classes of antibiotics as previously described [34].

\section{Biofilm assay}

The ability of $A$. baumannii isolates to produce biofilm was assessed by the microtiter plate method as previously described [35]. Briefly, biofilm formation was performed in triplicate from overnight cultures diluted in Tryptic soy broth (TSB) medium supplied with $1 \%$ glucose to an optical density (OD) of 0.01 at $600 \mathrm{~nm}$ and deposited in 96-well plates. TSB medium without inoculum was used as a negative control. The plate was incubated at $37^{\circ} \mathrm{C}$ for $24 \mathrm{~h}$ with gentle shaking. The wells were washed three times with Phosphate Buffer Saline (PBS) solution. Absolute methanol was added per well to biofilm fixation. Biofilm was stained with $1 \%$ crystal violet $(\mathrm{w} / \mathrm{v})$ and quantified at $595 \mathrm{~nm}$ after solubilization with absolute ethanol for $15 \mathrm{~min}$ at room temperature. Biofilm production was interpreted according to the criteria of Stepannovic et al. [36]. The optical density cutoff value (ODc) was established as three standard deviations (SD) above the mean of the optical density (OD) of the negative control as showed in the following formula: $\mathrm{ODc}=$ average $\mathrm{OD}$ of negative control+(3 SD of negative control).

The results were divided into the four following categories according to their optical densities as strong biofilm producer $(4 \mathrm{ODc}<\mathrm{OD})$; medium biofilm producer 
(2 ODc $<\mathrm{OD} \leq 4$ ODc); weak biofilm producer $(\mathrm{ODc}<$ $\mathrm{OD} \leq 2 \mathrm{ODc})$; and non-biofilm $(\mathrm{OD} \leq \mathrm{ODc})[36]$.

\section{Pulsed-field gel electrophoresis typing}

Genetic similarities among clinical and environmental isolates of $A$. baumannii were investigated by PFGE as previously described [37]. Briefly, an overnight culture of bacteria was suspended in $100 \mu \mathrm{l}$ of cell suspension buffer and was mixed with an identical volume of $2 \%$ low melting agarose and distributed in a plug mold. Genomic DNA in agarose plugs was lysed in the cell lysis solutions I and II, washed and digested with ApaI restriction enzyme (Thermo Scientific, USA). The Lambda PFG Ladder (New England, Biolabs) was used as a DNA size marker. Electrophoresis of digested DNA was performed in a pulsed-field electrophoresis system (Chef Mapper; Bio-Rad Laboratories, USA) by programming two states with the following conditions: temperature $14{ }^{\circ} \mathrm{C}$; voltage $6 \mathrm{~V} / \mathrm{cm}$; switch angle, $120^{\circ}$; switch ramp $2.2-35 \mathrm{~s}$ for $19 \mathrm{~h}$.

\section{Cluster analysis}

Gel images were studied by BioNumerics software version 7.5 (Applied Maths, StMartens-.

Latem, Belgium). Dendrograms were obtained for all of the isolates. A comparison of the banding patterns was done by the unweighted pair group method with mathematical averaging (UPGMA), and DNA similarity was considered by using the band-based Dice coefficient with a tolerance setting of $1.5 \%$ band tolerance and $1.5 \%$ optimization setting were applied during comparison of the DNA patterns. The PFGE results were compared according to the criteria by Tenover et al.; a PFGE cluster was based on a similarity cutoff of $80 \%$ [38].

\section{Statistical analysis}

Statistical analysis was performed using SPSS 23.0 (SPSS, Chicago, IL, USA). The frequency of susceptibility and biofilm formation category were determined in clinical and environmental isolates. The relationship among biofilm formation and the antibiotic resistance with PFGE type were made using chi-square tests. A $P$-value of less than 0.05 was considered as statistically significant.

\section{Abbreviations}

MDR: Multidrug-resistant; PFGE: Pulsed Field Gel Electrophoresis; ICUs: Intensive care units; XDR: Extensively drug resistant; CLSI: Clinical and Laboratory Standard Institute guidelines; TSB: Tryptic soy broth; OD: Optical density; PBS: Phosphate Buffer Saline

\section{Acknowledgments}

The authors would like to acknowledge Vice-chancellor of Research and Technology, Hamadan University of Medical Sciences, Hamadan, Iran, and microbiology laboratory staff.

\section{Authors' contributions}

MYA designed and organized this study and wrote the manuscript, PM performed the experiments, MRA revised the manuscript, AMB and SA collaborate in collecting samples and doing experiments. FK collaboration in introducing patients and clinical examination MK analyzing the statistical results of the study, AK improvement of the discussion and English editing of the revised manuscript. All authors have read and approved the manuscript.

\section{Funding}

This research was supported by a grant from Vice-chancellor of Research and Technology, Hamadan University of Medical Sciences, Hamadan, Iran (Grant Number: 9412187238).

The funder have no role in conducting this research.

\section{Availability of data and materials}

The datasets used and/or analyzed during the current study available from the corresponding author on reasonable request.

\section{Ethics approval and consent to participate}

The ethics committee of the Hamadan University of Medical Sciences approved the study protocol (Ethical approval code: IR.UMSHA.REC.1394.531). The Written consent was obtained from all participants.

\section{Consent for publication}

Not applicable.

\section{Competing interests}

The authors declare that they have no competing interests.

\section{Author details}

${ }^{1}$ Department of Microbiology, Faculty of Medicine, Hamadan University of Medical Sciences, Hamadan, Iran. ${ }^{2}$ Department of Microbiology, Faculty of Medicine, Kermanshah University of Medical Sciences, kermanshah, Iran. ${ }^{3}$ Department of Epidemiology, School of Public Health, Hamadan University of Medical Sciences, Hamadan, Iran. ${ }^{4}$ Department of Infectious Diseases, Faculty of Medicine, Hamadan University of Medical Sciences, Hamadan, Iran. ${ }^{5}$ Brucellosis Research Center, Hamadan University of Medical Sciences, Hamadan, Iran. ${ }^{6}$ Division of Human Genetics, Department of Anatomy, St. John's Hospital, Bangalore, India.

Received: 14 October 2019 Accepted: 19 April 2020

Published online: 25 April 2020

\section{References}

1. Ying C, Li Y, Wang Y, Zheng B, Yang C. Investigation of the molecular epidemiology of Acinetobacter baumannii isolated from patients and environmental contamination. J Antibiot. 2015;68(9):562-7.

2. Castilho SRA, de Miranda Godoy CS, Guilarde AO, Cardoso JL, André MCP, Junqueira-Kipnis AP, et al. Acinetobacter baumannii strains isolated from patients in intensive care units in Goiânia, Brazil: molecular and drug susceptibility profiles. PLoS One. 2017;12(5):e0176790.

3. Safari M, Nejad ASM, Bahador A, Jafari R, Alikhani MY. Prevalence of ESBL and MBL encoding genes in Acinetobacter baumannii strains isolated from patients of intensive care units (ICU). Saudi J Biological Sci. 2015;22(4):424-9.

4. Gong Y, Shen X, Huang G, Zhang C, Luo X, Yin S, et al. Epidemiology and resistance features of Acinetobacter baumannii isolates from the ward environment and patients in the burn ICU of a Chinese hospital. J Microbiol. 2016;54(8):551-8.

5. Li P, Li H, Lei H, Liu W, Zhao X, Guo L, et al. Rapid detection of Acinetobacter baumannii and molecular epidemiology of carbapenemresistant A. baumannii in two comprehensive hospitals of Beijing, China Front Microbiol. 2015;6:997.

6. Safari M, Saidijam M, Bahador A, Jafari R, Alikhani MY. High prevalence of multidrug resistance and metallo-beta-lactamase (MBL) producing Acinetobacter baumannii isolated from patients in ICU wards, Hamadan, Iran. J Res Health Sci. 2013;13(2):162-7.

7. Eliopoulos GM, Maragakis LL, Perl TM. Acinetobacter baumannii: epidemiology, antimicrobial resistance, and treatment options. Clin Infect Dis. 2008:46(8):1254-63.

8. Chen Z, Liu W, Zhang Y, Li Y, Jian Z, Deng H, et al. Molecular epidemiology of carbapenem-resistant Acinetobacter spp. from XiangYa hospital, in Hunan Province, China. J Basic Microbiol. 2013;53(2):121-7.

9. Kaliterna V, Kaliterna M, Hrenović J, Barišić Z, Tonkić M, Goic-Barisic I. Acinetobacter baumannii in southern Croatia: clonal lineages, biofilm formation, and resistance patterns. Infect Dis Ther. 2015;47(12):902-7. 
10. Dehbalaei MA, Najar-Peerayeh S, Taherikalani M, Behmanesh M. Clinical Isolates of Acinetobacter baumannii From Tehran Hospitals: Pulsed-field Gel Electrophoresis Characterization, Clonal Lineages, Antibiotic Susceptibility, and Biofilm-forming Ability. Jundishapur J Microbiol. 2017;10(7).

11. McConnell MJ, Actis L, Pachón J. Acinetobacter baumannii: human infections, factors contributing to pathogenesis and animal models. FEMS Microbiol Rev. 2013;37(2):130-55

12. Doughari HJ, Ndakidemi PA, Human IS, Benade S. The ecology, biology and pathogenesis of Acinetobacter spp.: an overview. Microbes Environ. 2011; 26(2):101-12.

13. Thom KA, Johnson JK, Lee MS, Harris AD. Environmental contamination because of multidrug-resistant Acinetobacter baumannii surrounding colonized or infected patients. Am J Infect Control. 2011;39(9):711-5.

14. Daef EA, Mohamad IS, Ahmad AS, El-Gendy SG, Ahmed EH, Sayed IM. Relationship between clinical and environmental isolates of Acinetobacter baumannii in Assiut University hospitals. J Am Sci. 2013;9(11s):67-73.

15. Lemmen S, Häfner H, Zolldann D, Stanzel S, Lütticken R. Distribution of multi-resistant gram-negative versus gram-positive bacteria in the hospital inanimate environment. J Hosp Infect. 2004;56(3):191-7.

16. Saffari F, Monsen T, Karmostaji A, Bahadori Azimabad F, Widerström M. Significant spread of extensively drug-resistant Acinetobacter baumannii genotypes of clonal complex 92 among intensive care unit patients in a university hospital in southern Iran. J Med Microbiol. 2017;66(11):1656-62.

17. Zeighami H, Valadkhani F, Shapouri R, Samadi E, Haghi F. Virulence characteristics of multidrug resistant biofilm forming Acinetobacter baumannii isolated from intensive care unit patients. BMC Infect Dis. 2019;19:629.

18. Hassan PA, Khider AK. Correlation of biofilm formation and antibiotic resistance among clinical and soil isolates of Acinetobacter baumannii in Iraq. Acta Microbiol Immunol Hung. 2019:1-10.

19. Behnia M, Logan SC, Fallen L, Catalano P. Nosocomial and ventilatorassociated pneumonia in a community hospital intensive care unit: a retrospective review and analysis. BMC Res Notes. 2014;7(1):1.

20. Ebrahimi M, Khansari-nejad B, Ghaznavi-Rad E. High frequency of ventilator associated pneumonia nosocomial co-infection caused by methicillin resistant Staphylococcus aureus and carbapenem resistant $A$. baumannii in intensive care unit. J Iranian Clin Res. 2015;1(2):67-71.

21. Uwingabiye J, Lemnouer A, Roca I, Alouane T, Frikh M, Belefquih B, et al. Clonal diversity and detection of carbapenem resistance encoding genes among multidrug-resistant Acinetobacter baumannii isolates recovered from patients and environment in two intensive care units in a Moroccan hospital. Antimicrob Resist Infect Control. 2017;6(1):99.

22. Gurung J, Khyriem AB, Banik A, Lyngdoh W, Choudhury B, Bhattacharyya P. Association of biofilm production with multidrug resistance among clinical isolates of Acinetobacter baumannii and Pseudomonas aeruginosa from intensive care unit. Indian J Critical Care Med. 2013;17(4):214.

23. Thummeepak R, Kongthai $P$, Leungtongkam U, Sitthisak S. Distribution of virulence genes involved in biofilm formation in multi-drug resistant Acinetobacter baumannii clinical isolates. Int Microbiol. 2016;19(2):121-9.

24. Youn SJ. Molecular characterization and antimicrobial susceptibility of biofilm-forming Acinetobacter baumannii clinical isolates from Daejeon, Korea. Korean J Clin Lab Sci. 2018:50(2):100-9.

25. Qi L, Li H, Zhang C, Liang B, Li J, Wang L, Du X, Liu X, Qiu S, Song H. Relationship between antibiotic resistance, biofilm formation, and biofilm specific resistance in Acinetobacter baumannii. Front Microbiol. 2016;7:483.

26. Babapour E, Haddadi A, Mirnejad R, Angaji S-A, Amirmozafari N. Biofilm formation in clinical isolates of nosocomial Acinetobacter baumannii and its relationship with multidrug resistance. Asian Pac J Trop Biomed. 2016;6(6): 528-33.

27. Chang K-M, Huang W-C, Chiou C-S, Shen G-H, Huang C-C, Wen F-S. Suitable restriction enzyme for standardization of pulsed-field gel electrophoresis protocol and interlaboratory comparison of Acinetobacter baumannii. J Microbiol Immunol Infect. 2013;46(3):195-201.

28. Rafei R, Dabboussi F, Hamze M, Eveillard M, Lemarié C, Gaultier M-P, et al. Molecular analysis of Acinetobacter baumannii strains isolated in Lebanon using four different typing methods. PLoS One. 2014;9(12):e115969.

29. Fournier PE, Richet $\mathrm{H}$. The epidemiology and control of Acinetobacter baumannii in health care facilities. Clin Infect Dis. 2006;42(5):692-9.

30. Wroblewska MM, Sawicka-Grzelak A, Marchel H, Luczak M, Sivan A. Biofilm production by clinical strains of Acinetobacter baumannii isolated frompatients hospitalized in two tertiary care hospitals. FEMS Immunol Med Microbiol. 2008:53(1):140-4.
31. Ying J, Lu J, Zong L, Li A, Pan R, Cheng C, et al. Molecular epidemiology and characterization of genotypes of Acinetobacter baumannii isolates from regions of South China. Japanese J Infect Dis. 2016;69(3):180-5 27.

32. Oh MH, Lee JC, Kim J, Choi CH, Han K. Simple method for markerless gene deletion in multidrug-resistant Acinetobacter baumannii. Appl Environ Microbiol. 2015;81(10):3357-68.

33. Performance standards for antimicrobial susceptibility testing. Wayne, PA: Clinical and Laboratory Standards Institute; 2018.

34. Azizi O, Shakibaie MR, Modarresi F, Shahcheraghi F. Molecular detection of class-D OXA carbapenemase genes in biofilm and non-biofilm forming clinical isolates of Acinetobacter baumannii. Jundishapur J Microbiol. 2015;8(1).

35. Bardbari AM, Arabestani MR, Karami M, Keramat F, Aghazadeh H, Alikhani MY, et al. Highly synergistic activity of melittin with imipenem and colistin in biofilm inhibition against multidrug-resistant strong biofilm producer strains of Acinetobacter baumannii. Eur J Clin Microbiol Infect Dis. 2018:1-12.

36. Stepanović S, Vuković D, Hola V, Bonaventura GD, Djukić S, Ćirković I, et al. Quantification of biofilm in microtiter plates: overview of testing conditions and practical recommendations for assessment of biofilm production by staphylococci. Apmis. 2007;115(8):891-9.

37. Mohajeri P, Farahani A, Feizabadi M, Norozi B. Clonal evolution multi-drug resistant Acinetobacter baumannii by pulsed-field gel electrophoresis. Indian J Med Microbiol. 2015:33(1):87.

38. Tenover FC, Arbeit RD, Goering RV, et al. Interpreting chromosomal DNA restriction patterns produced by pulsed-field gel electrophoresis: criteria for bacterial strain typing. J Clin Microbiol. 1995;33:2233-9.

\section{Publisher's Note}

Springer Nature remains neutral with regard to jurisdictional claims in published maps and institutional affiliations.
Ready to submit your research? Choose BMC and benefit from:

- fast, convenient online submission

- thorough peer review by experienced researchers in your field

- rapid publication on acceptance

- support for research data, including large and complex data types

- gold Open Access which fosters wider collaboration and increased citations

- maximum visibility for your research: over $100 \mathrm{M}$ website views per year

At $\mathrm{BMC}$, research is always in progress.

Learn more biomedcentral.com/submissions 